\title{
Equilibrium, Kinetic and Thermodynamic Studies of Europium Adsorption by Biopolymeric Composite
}

\author{
Cem GÖK
}

\begin{abstract}
Biopolymers materials can be used for many applications in various areas. In this study, prepared magnetic alginate/hydroxyapatite biopolymeric composites were used for removal of europium from aqueous solution. In this respect, the physicochemical parameters of adsorption process are investigated for optimum uptake conditions. Sorption mechanisms will be investigated using experimental results and calculated parameters from some models as thermodynamic, isothermal and kinetic. The results suggest that these materials were proven to be potent material with chemical adsorption mechanism for reducing the concentration of europium with high efficiency in aqueous solution. Due to the high sorption capacity as $\mathbf{2 5 0 . 0} \mathrm{mg} / \mathrm{g}$ of the prepared material, plus its easy preparation process, economic advantage and environmental friendly nature would make these composites a promising removal and recovery agent for lanthanides.
\end{abstract}

Index Terms-Biopolymer, europium, magnetic adsorbent, adsorption.

\section{INTRODUCTION}

Rare earth elements (REEs) have received considerable attention with their increasing demands due to its technological importance [1]. Europium belongs to the REEs; only their trivalent oxidation states are stable in aqueous solutions. Its chemical behaviors have been considered typical of REE and of some trivalent actinides as well. Europium (Eu) are used mainly in the manufacture of cathode ray tubes, fuorescent lamp, and screen for X-rays; in the nuclear industry europium is used as absorbent of neutrons for the extinction and control rods of the reactors. In the context of the safety of nuclear waste repositories, as well as for assessing radionuclide mobility in the environment or industrial wastes, the interaction among lanthanides and actinides with sorbents has become a main subject of many studies [2]-[3].

There is a need for an effective, environmental friendly and economical process to remove or recovery rare earth ions from aqueous solution. Many preconcentration and separation procedures based on adsorption processes are used in nuclear technology, industry, medicine and daily life. The use of biopolymers and microorganisms for the removal of metal ions and radionuclides provides an alternative means to existing technologies. The process of biosorption is a good alternative for sequestering lanthanides from aqueous solution because of its simple, relatively low-cost, effective

Manuscript received July 10, 2017; revised September 20, 2017. This work was supported in part by the Pamukkale University, Scientific Research Projects Unit (PAU BAP) under the project number of 2013BSP004.

C. Gök is with Pamukkale University, Department of of Electricity and Energy, 20070 Kinikli, Denizli, Turkey (e-mail: cemgok@pau.edu.tr). and environmental friendliness properties. Biosorption is a property of certain types of inactive, dead, microbial biomass to bind and concentrate heavy metals/radionuclides from even very dilute aqueous solutions [4]-[7]. Lanthanides or radionuclides sequestration by different parts of the cell can occur via; complexation, chelation of metals, adsorption, coordination, ion exchange and inorganic microprecipitation. It is particularly the cell wall structure of certain algae, fungi, yeast and bacteria which was found responsible for this phenomenon [8].

Hydroxyapatite (HA, $\left.\mathrm{Ca}_{10}\left(\mathrm{PO}_{4}\right)_{6}(\mathrm{OH})_{2}\right)$ has been identified as a promising material and an efficient adsorbent for the remediation technologies because of its high sorption capacity, biocompatibility, availability and low cost, high stability non-toxicity, and chemical inertness [9]. However, our previous studies have showed that hydroxyapatite has poor mechanical properties, used in the form of a fine powder dispersed in an aqueous solution. One of the things that can be done to improve mechanical and chemical properties and reusability is to prepare composite material. Our studies revealed that hydroxyapatite can be blended with alginate to overcome the deficiencies of hydroxyapatite and to combine the good characteristics of these two kinds of biomaterial. Beside this, adsorbents combining with magnetic properties are one of the most promising technologies, providing an efficient, fast and economical method for separation and remediation studies [9]-[10].

Magnetic alginate/hydroxyapatite biopolymeric composites have been used for the removal of europium from aqueous solution in this study. Some process parameters affecting the adsorption were discussed and thermodynamic parameters were calculated. In addition, different types of isotherm and kinetic models were calculated to clarify the adsorption mechanism of europium on prepared adsorbent.

\section{MATERIALS AND METHODS}

\section{A. Preparation of Adsorbent}

All chemicals used in this study were of commercially available analytical grade and used without further purification. Calcium nitrate tetrahydrate $\mathrm{Ca}\left(\mathrm{NO}_{3}\right)_{2} \cdot 4 \mathrm{H}_{2} \mathrm{O}$ and diammonium hydrogen phosphate $\left(\mathrm{NH}_{4}\right)_{2} \mathrm{HPO}_{4}$ were used for the preparation of hydroxyapatite. Hydroxyapatite powder was chemically synthesized by wet chemical precipitation method [9]. The magnetite particles were also obtained by co-precipitation [11]. A suspension of magnetite was prepared in acetic acid solution (2.0 wt\%) and then separated and dried. Magnetic nanoparticles $\left(\mathrm{Fe}_{3} \mathrm{O}_{4}\right)$ were $100 \mathrm{~nm}$ average particle sizes.

Biocomposites were prepared by dropwise addition of $2 \%$ 
of viscous sodium alginate solution (w/v), hydroxyapatite and magnetite mixture to $0,5 \mathrm{~mol} / \mathrm{L} \quad \mathrm{CaCl}_{2}$ solution, maintaining the temperature at $4{ }^{0} \mathrm{C}$. After 1 hour stirring, the resulting gel beads were stored in $0.5 \mathrm{~mol} / \mathrm{L} \mathrm{CaCl}_{2}$ solution for 1 hour at room temperature. Na-alginate reacts with $\mathrm{CaCl}_{2}$ to form beads and Ca cross-linked alginate was formed [7]. Also, hydroxyapatite and magnetite were enclosed in beads. By doing so, the water soluble sodium alginate was converted into water insoluble calcium alginate beads. The resultant beads were stored after washing with de-ionized water to remove $\mathrm{CaCl}_{2}$ from the bead surfaces. The beads were collected by filtration and the excess water was adsorbed on filter paper. The beads were then dried at room temperature for $48 \mathrm{~h}$. The loss of weight after drying was $97 \%$ and was accompanied by a diameter reduction of alginate beads from 3 to $0.5 \mathrm{~mm}$. The advantages of using dry bead composites instead of the gel type are ease of handling and storage, greater precision during weighing and greater stiffness.

\section{B. Adsorption Studies}

Stock solutions of europium were prepared by dissolving an appropriate amount of $\mathrm{Eu}\left(\mathrm{NO}_{3}\right)_{3} \cdot 6 \mathrm{H}_{2} \mathrm{O}$ in deionized water. The adsorption experiments were carried out in $50 \mathrm{~mL}$ polyethylene flask containing $25 \mathrm{~mL}$ of europium solution with $25 \mathrm{mg}$ of adsorbent, unless otherwise stated by batch technique. Flasks were agitated on a thermostated shaker bath at selected $\mathrm{pH}$, constant temperature and predetermined time intervals. $0.01-1 \mathrm{~mol} / \mathrm{L} \mathrm{HCl}$ and $\mathrm{NaOH}$ solutions were used for $\mathrm{pH}$ adjustment. After the establishment of adsorption equilibrium, the adsorbents were separated from the solutions using a permanent magnet. Afterwards, concentration of europium in aqueous solution was determined spectrophotometrically. UV-1601 model Shimadzu UV-vis spectrophotometer was used to determine Eu(III)-arsenazo III complex. $0.1 \%$ arsenazo III (Sigma-Aldrich) solution was prepared by dissolving $100 \mathrm{mg}$ of the reagent in $100 \mathrm{~mL}$ of doubly deionized water. Concentrations of europium were determined spectrophotometrically at $653.5 \mathrm{~nm}$ according to Lambert-Beer law after the addition of $4 \mathrm{~mL}$ of hydrochloric acid-potassium chloride buffer and $0.4 \mathrm{~mL}$ of arsenazo III to appropriate amount of europium solution in a total volume of $10 \mathrm{~mL}$. The amount of adsorbed europium $\left(q_{e}, \mathrm{mg} / \mathrm{g}\right)$ was calculated by a mass balance relationship:

$$
q_{e}(\mathrm{mg} / \mathrm{g})=\frac{\left(C_{i}-C_{e}\right) V}{m}
$$

where $C_{i}$ and $C_{e}$ are the initial and equilibrium concentrations of europium (mg/L) in solutions, respectively. $m$ is the weight of the adsorbent (g), $V$ is the volume of the aqueous phase $(\mathrm{mL})$. Each experiment was repeated at least three times and the results were given at the average values. The relative errors of the data were less than $3 \%$.

\section{RESUlTS AND DisCUSSION}

\section{A. Effect of Initial $\mathrm{pH}$}

The value of $\mathrm{pH}$ of the aqueous solution is identified as the most important variable governing adsorption of the metal ions. The effect of initial $\mathrm{pH}$ on the adsorption of europium was investigated with $25 \mathrm{mg}$ of adsorbent, at $25^{\circ} \mathrm{C}$ and a contact time of $120 \mathrm{~min}$ for Eu concentration of $100 \mathrm{mg} / \mathrm{L}$.
The initial $\mathrm{pH}$ influence determined at different $\mathrm{pH}$ values ranging from 2.0 to 7.0 on adsorption process. As seen in Fig. 1 , europium ions adsorption increases with $\mathrm{pH}$ and approaches a steady state above $\mathrm{pH}$ 6.0. At $\mathrm{pH}$ higher than 7.0 is not considered because a precipitation occurred in the solution, indicates the hydrolysis of the metal ion with the formation of the corresponding insoluble hydroxide [12]. The adsorption capacity is low at strong acidic conditions at low $\mathrm{pH}$ values $(\mathrm{pH}<3.5)$, in which protons are strongly competing with adsorbates. The maximum adsorption for Eu(III) ions occurred at $\mathrm{pH}$ 6.0. So, this $\mathrm{pH}$ is selected for further experiments as an optimum value.

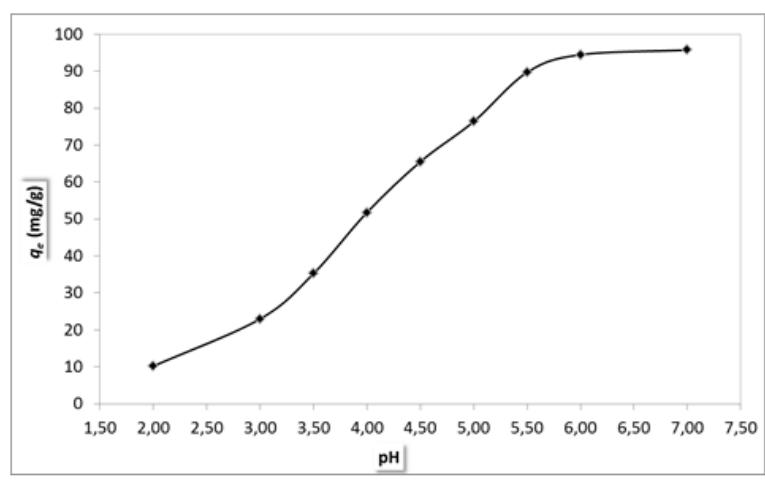

Fig. 1. Effect of initial pH for adsorption of Eu on adsorbent.

\section{B. Adsorption Equilibrium and Isotherm Models}

The equilibrium data of the adsorption process is essential to develop an equation that can be used to compare different adsorbents under different operational conditions and to design and optimize an operating procedure [13]. The adsorption process is a mass transfer operation that can be described mathematically by an equilibrium process and a rate process. The equilibrium is established between the concentration of the metal ions dissolved in aqueous phase and that bound to the adsorbent [14]. In this study, four widely-used adsorption isotherm models (Langmuir, Freundlich, Dubinin-Radushkevich and Temkin) were used to describe the adsorption equilibrium. The constants of isotherm models along with correlation coefficients $\left(R^{2}\right)$ have been calculated from the plots for adsorption of $\mathrm{Eu}$ on the adsorbent and the results.

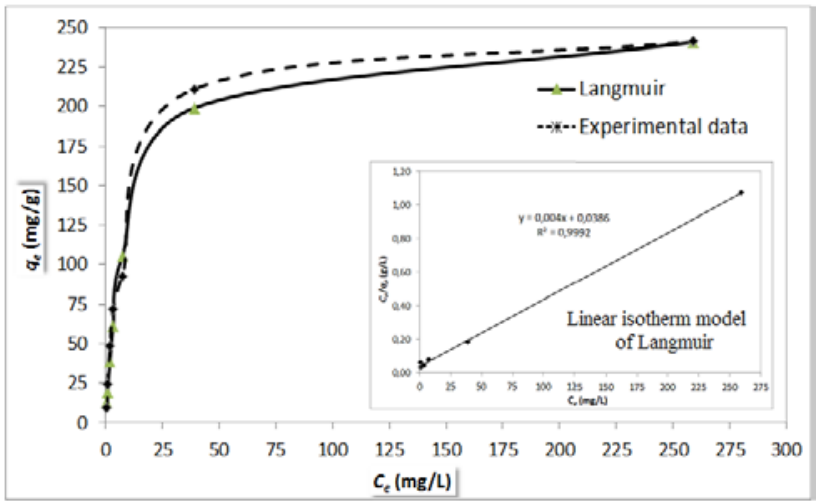

Fig. 2. Experimental equilibrium and Langmuir model curve for adsorption of Eu on adsorbent.

Adsorption equilibrium and the effect of Eu concentration on adsorption process were investigated and shown in Fig. 2. Adsorption equilibrium in the concentration range of 10-500 
$\mathrm{mg} / \mathrm{L}$ was studied with $25 \mathrm{mg}$ of composite adsorbent at $25^{\circ} \mathrm{C}$, pH 6.0 and 120 min contact time. The amount of adsorbed ions gradually increases by increasing the initial metal concentration in solution. This increase starts to dwindle away after $200 \mathrm{mg} / \mathrm{L}$ of initial Eu concentrations. This trend is probably due to the saturation of adsorption site of composite material at higher concentrations.

The Langmuir isotherm is probably the most widely used model. This model's theory assumes monolayer coverage of adsorbate over a homogeneous adsorbent surface [15]. Linearized equation of Langmuir model is given as follows:

$$
\frac{C_{e}}{q_{e}}=\frac{1}{Q_{0} b_{L}}+\frac{C_{e}}{Q_{0}}
$$

where $q_{e}$ is the amount of metal ions adsorbed onto adsorbent, $C_{e}$ is the equilibrium concentration of europium in solution, and $Q_{0}$ and $b_{L}$ are Langmuir constants related to adsorption capacity and adsorption energy, respectively. $Q_{0}$ and ${ }^{b} L$ were calculated from the slope and intercept of linear plots of $C_{e} / q_{e}$ versus $C_{e}$ (Fig. 2) [9].

The Freundlich isotherm assumes an empirical expression encompassing the surface heterogeneity and the exponential distribution of the energy of active sites [16]. This model can be represented as follows:

$$
\log q_{e}=\log K_{F}+\frac{1}{n_{F}} \log C_{e}
$$

where $K_{F}$ represents the adsorption capacity (mg/g), ${ }_{F}^{n}$ is a constant related to adsorption intensity (dimensionless). Linear plot of $\log q_{e}$ versus $\log C_{e}$ shows the applicability of this isotherm for Eu adsorption onto adsorbent [9].

The other widely used equation for the analysis of isotherms is Dubinin-Radushkevich (D-R) model [17]. This model, used to estimate the apparent free energy of adsorption, proposed an equation to find out the adsorption mechanism on the basis of the potential theory assuming a heterogeneous surface. The linearized form of the D-R isotherm is given as:

$$
\ln C_{a d s}=\ln X_{\mathrm{m}}-\beta \varepsilon^{2}
$$

where $C_{a d s}(\mathrm{mmol} / \mathrm{g})$ is the amount of solute adsorbed per unit weight of solid, $X_{m}(\mathrm{mmol} / \mathrm{g}$ or $\mathrm{mg} / \mathrm{g}$ ) is the adsorption capacity, $\beta(\mathrm{mol} / \mathrm{K})^{2}$ is a constant related to energy and $\varepsilon$ is the Polanyi potential. Polanyi potential can be computed by the following equation:

$$
\varepsilon=R T \ln \left(\frac{1}{1+C_{e}}\right)
$$

where $R$ is a gas constant in $\mathrm{kJ} / \mathrm{mol}$ and $T$ is the temperature in Kelvin. If $\ln C_{a d s}$ is plotted against $\varepsilon^{2}, \beta$ and $X_{m}$ can be obtained from the slope and intercept, respectively. The mean energy of adsorption $(E)$ is calculated by the following equation using the constant $\beta$ [9].

$$
E=\frac{1}{\sqrt{-2 \beta}}
$$

Isotherm constants and mean free energy of the Dubinin-
Radushkevich model are shown in Table I. Adsorption capacities $\left(X_{m}\right)$ of this model were calculated as $253.6 \mathrm{mg} / \mathrm{g}$. These value are compatible with experimental results and also with the other models. The magnitude of $E$ is used to estimate the reaction mechanism of adsorption process. If value of $E$ is between 1 and $8 \mathrm{~kJ} / \mathrm{mol}$, it indicates a physical adsorption. If value of $E$ is higher than $8 \mathrm{~kJ} / \mathrm{mol}$, the adsorption process is of a chemical nature [18]. The $E$ value of $\mathrm{Eu}$ adsorption obtained as $17.8 \mathrm{~kJ} / \mathrm{mol}$. This value indicates that the magnitudes of $E$ value are in the energy range of chemisorption.

TABLE I: CONSTANTS OF ISOTHERM MODELS FOR EU ADSORPTION

\begin{tabular}{lll}
\hline \hline Isotherm models & Parameters & Value \\
\hline \multirow{3}{*}{ Langmuir } & $Q_{o}(\mathrm{mg} / \mathrm{g})$ & 250.0 \\
& $b_{\mathrm{L}}(\mathrm{L} / \mathrm{mg})$ & 0.10 \\
& $R^{2}$ & 0.9992 \\
\hline \multirow{2}{*}{ Freundlich } & $K_{F}(\mathrm{mg} / \mathrm{g})$ & 26.8 \\
& $n_{F}$ & 2.1 \\
& $R^{2}$ & 0.8430 \\
\hline \multirow{3}{*}{ Dubinin- Radushkevich } & $X_{m}(\mathrm{mg} / \mathrm{g})$ & 253.6 \\
& $\beta(\mathrm{mol} / \mathrm{kJ})^{2}$ & $1.6 \times 10^{-3}$ \\
& $E(\mathrm{~kJ} / \mathrm{mol})$ & 17.8 \\
& $R^{2}$ & 0.9227 \\
\hline \multirow{2}{*}{ Temkin } & $b_{T e}(\mathrm{~J} / \mathrm{mol})$ & 9.2 \\
& $a_{T e}(\mathrm{~L} / \mathrm{mg})$ & 6.9 \\
\hline \hline
\end{tabular}

The Temkin isotherm assumes that the heat of adsorption of all the molecules in the layer decreases linearly with coverage due to adsorbent-adsorbate interactions. The adsorption is characterized by a uniform distribution of the binding energies, up to some maximum binding energy [19]. A linear form of the Temkin equation is given as:

$$
q_{e}=\frac{R T}{b_{T e}} \ln a_{T e}+\frac{R T}{b_{T e}} \ln C_{e}
$$

where $b_{T e}$ is the Temkin constant related to heat of adsorption $(\mathrm{J} / \mathrm{mol}) ; a_{T e}$ the Temkin isotherm constant $(\mathrm{L} / \mathrm{mg}), R$ the gas constant and $T$ the absolute temperature (K). The plot of the $q_{e}$ versus $\ln C_{e}$ gives a straight line and $b_{T e}$ and $a_{T e}$ constants can be calculated from the intercept and slope [9].

The high correlation coefficient $\left(R^{2}\right)$ value, given in Table $I$, indicated that the experimental data fitted satisfactorily the Langmuir model. The Langmuir model assumes that the sorption of adsorbate onto the surfaces of the adsorbent happens through a monolayer adsorption on a homogeneous surface. The maximum monolayer adsorption capacities of Eu on prepared composite were found to be $250 \mathrm{mg} / \mathrm{g}$. It is also apparent that Freundlich, Dubinin-Radushkevich and Temkin isotherm models does not provide a particularly good model for the adsorption of Eu considering the comparative magnitudes of correlation coefficients together with the isotherm constants.

\section{Effect of Temperature and Thermodynamic Studies}

The effect of temperature was studied on the adsorption of Eu by composite material in the range of $20-50{ }^{\circ} \mathrm{C}$, at $\mathrm{pH} 6.0$, and contact time of $120 \mathrm{~min}$ for the initial Eu concentration of $100 \mathrm{mg} / \mathrm{L}$ and $25 \mathrm{mg}$ of adsorbent. As seen Fig. 3, adsorption process of $\mathrm{Eu}$ is appeared to be temperature dependent over 
the temperature range tested. Based on these results, adsorption of Eu was endothermic in nature. The increase in the amount of adsorbed europium at increased temperature might be due to the higher affinity of available active sites or the energy of the system facilitated europium sorption on the surface of the composite at high temperatures [18]-[19].

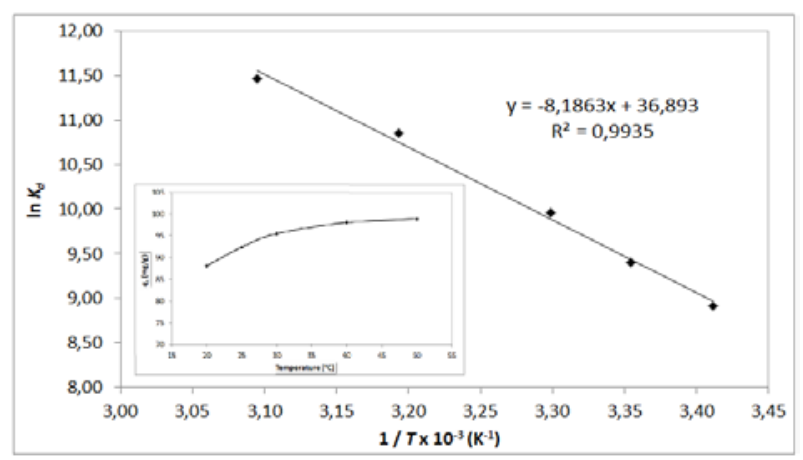

Fig. 3. Van't Hoff plot and effect of temperature for adsorption of Eu on adsorbent.

Thermodynamic parameters such as enthalpy change $\left(\Delta H^{\circ}\right)$, entropy change $\left(\Delta S^{\circ}\right)$ and free energy change $\left(\Delta G^{\circ}\right)$ were estimated using the following equations.

$$
\begin{aligned}
& \ln K_{d}=\frac{\Delta S^{0}}{R}-\frac{\Delta H^{0}}{R T} \\
& \Delta G^{0}=\Delta H^{0}-T \Delta S^{0}
\end{aligned}
$$

where $K_{d}$ is the distribution coefficient, $T$ is the temperature in Kelvin, and $R$ is the gas constant $(8.314 \mathrm{~J} / \mathrm{mol} \mathrm{K})$. The values of $\Delta H^{\circ}$ and $\Delta S^{\circ}$ were determined from the slopes and intercepts of the plots of $\ln K_{d}$ vs. $1 / \mathrm{T}$ by using Eq. (8). The plot of $\ln K_{d}$ against $1 / \mathrm{T}$ for europium adsorption is shown in Fig. 3. Gibbs free energy $\left(\Delta G^{\circ}\right)$ was calculated for each working temperature by using Eq. (9) [18]. Distribution coefficient $\left(K_{d}, \mathrm{~mL} / \mathrm{g}\right)$ is also computed using the following equation:

$$
K_{d}(\mathrm{~mL} / \mathrm{g})=\frac{C_{i}-C_{e}}{C_{e}} \times \frac{V}{m}
$$

where $C_{i}$ and $C_{e}$ are the initial and equilibrium concentrations of $\mathrm{Eu}(\mathrm{mg} / \mathrm{L})$ in solutions. $m$ is the weight of the adsorbent $(\mathrm{g})$, $V$ is the volume of the aqueous phase $(\mathrm{mL})$. The calculated values of the thermodynamic parameters for the adsorption of Eu(III) are given in Table II.

The positive values of the enthalpy change suggest that the endothermic nature of the adsorption process. When the value of $\Delta H^{\circ}$ is higher than $40 \mathrm{~kJ} / \mathrm{mol}$, the type of adsorption can be accepted as chemical process [20]. $\Delta H^{\circ}$ value of Eu adsorption is calculated as $68.06 \mathrm{~kJ} / \mathrm{mol}$. It can be interpreted from this value that chemisorption is the mechanism of adsorption reaction. This result is also consistent with the results found from isotherm models.

TABLE II: THERMODYNAMIC PARAMETERS FOR ADSORPTION OF EU

\begin{tabular}{lccccc}
\hline \hline \multicolumn{3}{c}{ Variation of Enthalpy $\left(\Delta H^{\circ}\right)$} & \multicolumn{3}{c}{$68,06 \mathrm{~kJ} / \mathrm{mol}$} \\
\hline \multicolumn{3}{c}{ Variation of Entropy $\left(\Delta S^{\circ}\right)$} & \multicolumn{3}{c}{$306,74 \mathrm{~J} / \mathrm{mol} \mathrm{K}$} \\
\hline $\begin{array}{l}\text { Gibbs Free Energy } \\
\left(\Delta G^{\circ}\right)(\mathrm{kJ} / \mathrm{mol})\end{array}$ & $-293 \mathrm{~K}$ & $298 \mathrm{~K}$ & $303 \mathrm{~K}$ & $313 \mathrm{~K}$ & $323 \mathrm{~K}$ \\
\cline { 2 - 6 } & $-23,86$ & $-23,39$ & $-24,93$ & $-27,99$ & $-31,06$ \\
\hline \hline
\end{tabular}

The positive value of entropy change indicates the increased randomness at the solid-solution interface during the adsorption of europium on adsorbents. The positive entropy favors complexation and stability of adsorption. The negative values for the Gibbs free energy change show that the adsorption process is thermodynamically feasible and the degree of spontaneity of the reaction increases with increasing temperature as seen in Table II. This is indicating that the adsorption reaction is spontaneous and more favorable at higher temperature. The obtained negative standard Gibbs energy changes indicate that the adsorption reactions are greatly driven towards the products. The increase in adsorption with temperature may be attributed to either increase in the number of active surface sites available for adsorption on the adsorbents or the desolvation of the sorbing species. The decrease in the thickness of the boundary layer surrounding the adsorbent with temperature, so that the mass transfer resistance of adsorbate in the boundary layer decreases [21]-[22].

\section{Effect of Contact Time and Kinetic Studies}

The effect of contact time on the adsorption of Eu(III) onto composite material was studied in the range of $15-240 \mathrm{~min}$ using $100 \mathrm{mg} / \mathrm{L}$ initial europium concentration at $\mathrm{pH}$ 6.0. Fig. 4 shows that the sorption yield slightly increases with increasing contact time within $90 \mathrm{~min}$. The result of this study showed that the uptake of europium was rapid. Then the adsorption remains constant level with increasing time.

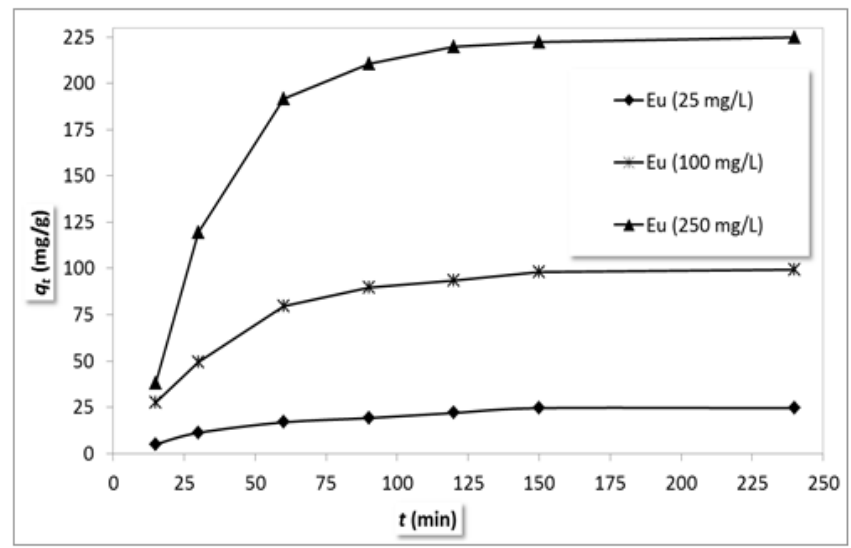

Fig. 4. The effect of contact time on the adsorption of Eu at different initial concentrations.

The adsorption kinetic shows the evolution of the adsorption capacity with time. Pseudo-first-order and pseudo-second-order models were used to test the experimental data to examine the potential rate-controlling step. Kinetic parameters of the Eu adsorption process at different concentration can be seen Table III. The employed pseudo-first order (Lagergren's) rate equation is given by;

$$
\log \left(q_{e}-q_{t}\right)=\log q_{e}-\frac{k_{1} t}{2.303}
$$

where $q_{e}$ is the amount of metal ion adsorbed onto adsorbent at equilibrium (mg/g), $q_{t}$ is the amount of metal ion adsorbed at various times, $t$ is the time of adsorption duration and $k_{1}$ is the rate constant of the equation $\left(\mathrm{min}^{-1}\right)$ [23]. Slopes and intercepts of plots of $\log \left(q_{e}-q_{t}\right)$ vs. time were obtained for adsorbent to determine the first-order rate constant $k_{1}$ at different $\mathrm{Eu}(\mathrm{III})$ concentrations. 
The pseudo-second-order model can be represented in the following form by:

$$
\frac{t}{q_{t}}=\frac{1}{k_{2} q_{e}^{2}}+\frac{t}{q_{e}}
$$

where $k_{2}$ (g/mol min) is the second-order rate constant. The linear plot of $t / q_{t}$ as a function of t provided not only the rate constant $k_{2}$, but also an independent evaluation of $q_{e}$. The pseudo-second-order rate constant $k_{2}$ was determined from the slopes and intercepts of plots of t/q vs. (Fig. 5) [18]-[23].

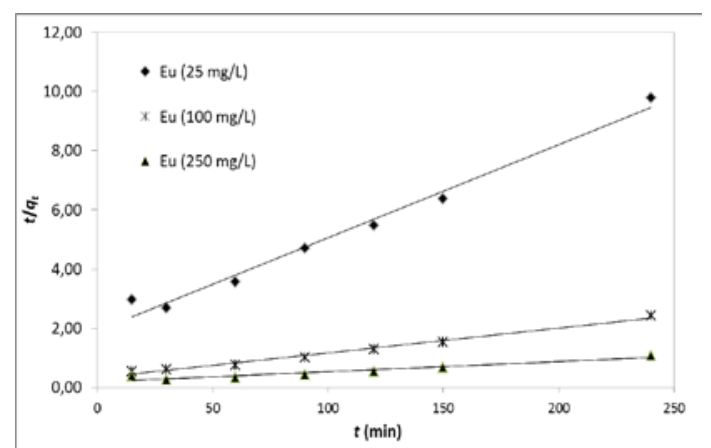

Fig. 5. The pseudo-second-order kinetic model plot of Eu adsorption at different initial concentrations.

TABLE III: KINETIC PARAMETERS AT DIFFERENT CONCENTRATION OF EU

\begin{tabular}{llllc}
\hline \hline Kinetic models & $\mathrm{Ci}(\mathrm{mg} / \mathrm{L})$ & $k_{1}\left(\mathrm{~min}^{-1}\right)$ & $q_{e}(\mathrm{mg} / \mathrm{g})$ & $R^{2}$ \\
\hline \multirow{2}{*}{$\begin{array}{l}\text { Pseudo-first } \\
\text { order equation }\end{array}$} & 25 & 0.021 & 27.28 & 0.978 \\
& 250 & 0.027 & 111.20 & 0.975 \\
& $C_{i}(\mathrm{mg} / \mathrm{L})$ & $k_{2}(\mathrm{~g} / \mathrm{mg} \mathrm{min})$ & $q_{e}(\mathrm{mg} / \mathrm{g})$ & $R^{2}$ \\
\hline Pseudo-second & 25 & $5.21 \times 10^{-4}$ & 31.75 & 0.983 \\
order equation & 100 & $2.25 \times 10^{-4}$ & 119.05 & 0.988 \\
& 250 & $6.35 \times 10^{-5}$ & 264.12 & 0.998 \\
\hline \hline
\end{tabular}

The correlation coefficients for the first-order kinetic model at different concentrations as seen Table III were relatively low, and indicating that the adsorption of $\mathrm{Eu}(\mathrm{III})$ ions onto adsorbent fits well pseudo-second-order. For this reason, the rate-limiting step may be chemical sorption or chemisorption through sharing or exchange of electrons between sorbent and adsorbate [20]. Beside this, the rate constant of pseudo-second order $\left(k_{2}\right)$ was found to decrease with increasing initial metal ion concentrations (Table III). That is, time required for the equilibrium adsorption increased with minute differences as initial metal ions concentration increased. It means that the adsorption rates of europium are faster at low concentrations. The competition for the surface active sites of the adsorbent will be high at higher concentrations and after all lower sorption rates are obtained [9]-[18].

\section{CONCLUSION}

Search for efficient, cost-effective and high-strength adsorbents has become an important and urgent problem in removal of metals and radionuclides. Aiming at the removal of europium ions from aqueous solutions in this sense, magnetic alginate/hydroxyapatite biopolymeric composites were successfully applied in a batch system. The adsorption rate was highly dependent on operating variables such as initial solution $\mathrm{pH}$, initial metal concentration, contact time and temperature. The optimum $\mathrm{pH}$ for the effective removal of Eu(III) was founded as 6.0 and the adsorption of element reaches equilibrium within $120 \mathrm{~min}$. The adsorption equilibrium follows Langmuir isotherms model and the maximum adsorption capacities were founded as $250.0 \mathrm{mg} / \mathrm{g}$. The process has endothermic nature and more favorable at higher temperatures. Adsorption kinetics followed the pseudo-second-order kinetic model and the mechanisms of $\mathrm{Eu}(\mathrm{III})$ adsorption are dominated by chemical adsorption.

On the basis of the data, it can be concluded that prepared magnetic alginate/hydroxyapatite biopolymeric composites can be used effectively for the removal of europium ions from aqueous solution using adsorption method with high capacity, environmental benign and economic properties, and also magnetic separation advantage. On the other hand, there is a need to develop innovative, more effective and selective adsorbents both for industry and the environment.

\section{REFERENCES}

[1] Ş. Sert, C. Kütahyali, S. İnan, Z. Talip, B. Çetinkaya, and M. Eral, "Biosorption of lanthanum and cerium from aqueous solutions by Platanus orientalis leaf powder,” Hydrometallurgy, vol. 90, no. 1, pp. 13-18, Jan. 2008.

[2] F. Granados-Correa, J. Vilchis-Granados, M. Jiménez-Reyes, L. A. Quiroz-Granados, and L. A. Quiroz-Granados, “Adsorption behaviour of $\mathrm{La}(\mathrm{III})$ and $\mathrm{Eu}(\mathrm{III})$ ions from aqueous solutions by hydroxyapatite: kinetic, isotherm, and thermodynamic studies," J. Chem., vol. 2013, pp. 1-9, 2013.

[3] J.-C. G. Bünzli and G. R. Choppin, Lanthanide Probes in Life, Chemical, and Earth Sciences : Theory and Practice, Elsevier, 1989.

[4] C. Gok and S. Aytas, "Chapter 16 - biosorption of uranium and thorium by biopolymers," The Role of Colloidal Systems in Environmental Protection, pp. 363-395, 2014.

[5] T. Davis, B. Volesky, and A. Mucci, "A review of the biochemistry of heavy metal biosorption by brown algae,” Water Res., vol. 37, no. 18, pp. 4311-4330, Nov. 2003.

[6] C. Gok, U. Gerstmann, and S. Aytas, "Biosorption of radiostrontium by alginate beads: Application of isotherm models and thermodynamic studies,” J. Radioanal. Nucl. Chem., vol. 295, no. 1, pp. 777-788, May 2013.

[7] C. Gok and S. Aytas, "Biosorption of uranium(VI) from aqueous solution using calcium alginate beads,” J. Hazard. Mater., vol. 168, no. 1, pp. 369-375, Aug. 2009.

[8] T. Ramachandra, N. Ahalya, and R. Kanamadi, Biosorption: Techniques and Mechanisms, pp. 1-91, 2005.

[9] C. Gok, "Neodymium and samarium recovery by magnetic nano-hydroxyapatite,” J. Radioanal. Nucl. Chem., vol. 301, no. 3, pp. 641-651, May 2014.

[10] D. Wu, L. Zhang, L. Wang, B. Zhu, and L. Fan, "Adsorption of lanthanum by magnetic alginate-chitosan gel beads,” J. Chem. Technol. Biotechnol., vol. 86, no. 3, pp. 345-352, Mar. 2011.

[11] A. M. Donia, A. A. Atia, and K. Z. Elwakeel, "Selective separation of mercury(II) using magnetic chitosan resin modified with Schiff's base derived from thiourea and glutaraldehyde,” J. Hazard. Mater., vol. 151, no. 2, pp. 372-379, 2008.

[12] M. C. Palmieri, B. Volesky, and O. Garcia, "Biosorption of lanthanum using sargassum fluitans in batch system,” Hydrometallurgy, vol. 67, no. 1, pp. 31-36, 2002.

[13] Y. Khambhaty, K. Mody, S. Basha, and B. Jha, "Kinetics, equilibrium and thermodynamic studies on biosorption of hexavalent chromium by dead fungal biomass of marine Aspergillus niger," Chem. Eng. J., vol. 145, no. 3, pp. 489-495, Jan. 2009.

[14] G. Bayramoglu, "Biosorption of heavy metal ions on immobilized white-rot fungus trametes versicolor,” J. Hazard. Mater., vol. 101, no. 3, pp. 285-300, Aug. 2003.

[15] I. Langmuir, "The adsorption of gases on plane surfaces of glass, mica and platinum,” J. Am. Chem. Soc., vol. 40, no. 9, pp. 1361-1403, Sep. 1918.

[16] H. Freundlich, “Adsorption in solution,” Zeitschrift für Phys. Chemie, vol. 57, pp. 384-410, 1906.

[17] L. V. Dubinin, M. M. Zaverina, and E. D. Radushkevich, "Sorption and structure of active carbons I. Adsorption of organic vapors,” Zhurnal Fiz. Khimii, vol. 21, pp. 1351-1362, 1947. 
[18] S. Yusan, C. Gok, S. Erenturk, and S. Aytas, “Adsorptive removal of thorium (IV) using calcined and flux calcined diatomite from Turkey: Evaluation of equilibrium, kinetic and thermodynamic data," Appl. Clay Sci., vol. 67-68, pp. 106-116, Oct. 2012.

[19] M. J. Temkin and V. Pyzhev, "Recent modifications to Langmuir isotherms," Acta Physiochim, vol. 12, pp. 217-222, 1940.

[20] Y. Ho and G. McKay, "Pseudo-second order model for sorption processes,” Process Biochem., vol. 34, no. 5, pp. 451-465, 1999.

[21] S. Aytas, M. Yurtlu, and R. Donat, "Adsorption characteristic of U(VI) ion onto thermally activated bentonite," J. Hazard. Mater., vol. 172, no. 2-3, pp. 667-674, Dec. 2009.

[22] B. Singha and S. K. Das, "Biosorption of $\mathrm{Cr}(\mathrm{VI})$ ions from aqueous solutions: Kinetics, equilibrium, thermodynamics and desorption studies,” Colloids Surfaces B Biointerfaces, vol. 84, no. 1, pp. 221-232, 2011.

[23] B. H. Hameed, J. M. Salman, and A. L. Ahmad, “Adsorption isotherm and kinetic modeling of 2,4-D pesticide on activated carbon derived from date stones,” J. Hazard. Mater., vol. 163, no. 1, pp. 121-126, Apr. 2009.

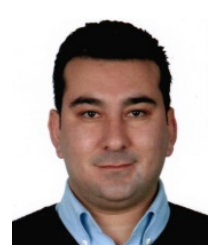

Cem GOK was born in Soke/Turkey. He received his bachelor degree in chemistry in the year 2002 from Ege University, Turkey. He got his master degree in analytical chemistry from Dokuz Eylul University. He received his $\mathrm{PhD}$ degree in Ege University, Institute of Nuclear Sciences, Department of Nuclear Technology in Izmir, Turkey in 2010.

He worked in Ege University and Pamukkale University in Turkey and also Helmholtz Zentrum München, Institute of Radiation Protection in Germany as a research assistant. He is currently serving as head and associate professor at the Department of Electricity and Energy, Pamukkale University, Denizli. His research interests include lanthanides and actinides chemistry, separation processes and environmental science, nuclear technologies and alternative energy resources. 